Article

\title{
Phytotoxicity and Accumulation of Antibiotics in Water Lettuce (Pistia stratiotes) and Parrot Feather (Myriophyllum aquaticum) Plants under Hydroponic Culture Conditions
}

\author{
Young-Jae Park ${ }^{1}$ and Jae-Gwon Son ${ }^{2, *}$ \\ 1 Horse Industry Complex Center, Jeonju Kijeon College, Jeonju 54989, Korea; song352@naver.com \\ 2 Department of Rural Construction Engineering, Jeonbuk National University, Jeonju 54906, Korea \\ * Correspondence: sjg@jbnu.ac.kr
}

check for updates

Citation: Park, Y.-J.; Son, J.-G. Phytotoxicity and Accumulation of Antibiotics in Water Lettuce (Pistia stratiotes) and Parrot Feather (Myriophyllum aquaticum) Plants under Hydroponic Culture Conditions. Appl. Sci. 2022, 12, 630. https://doi.org/10.3390/ app12020630

Academic Editors: Dibyendu Sarkar, Rupali Datta, Prafulla Kumar Sahoo and Mohammad

Mahmudur Rahman

Received: 13 December 2021

Accepted: 7 January 2022

Published: 10 January 2022

Publisher's Note: MDPI stays neutral with regard to jurisdictional claims in published maps and institutional affiliations.

Copyright: (c) 2022 by the authors. Licensee MDPI, Basel, Switzerland. This article is an open access article distributed under the terms and conditions of the Creative Commons Attribution (CC BY) license (https:/ / creativecommons.org/licenses/by/ $4.0 /)$.

\begin{abstract}
The aim of this research was to investigate the accumulation of antibiotics in two kinds of plants. The hydroponic culture solution included a mixture of antibiotics, including three commonly used antibiotics in South Korea: norfloxacin (NOR), sulfamethazine (SMZ), and tetracyclines (TC). None of these antibiotics were detected in the shoots of water lettuce plants, only in the roots. However, in parrot feather plants, antibiotics were detected in both the shoots and the roots, with higher amounts detected in the shoots than in the roots. SMZ and TC were most likely to be detected in the roots and shoots of water lettuce and parrot feather plants, and about one-third of the NOR administered was later detected in the plants. The BCF (bioconcentration factor) of antibiotics ranged from 0.24 to 0.78 , while that of NOR was much lower, ranging from 0.24 to 0.38 . The SMZ (0.59-0.64) and TET (0.72-0.78) exhibited higher uptake accumulation in the water lettuce tissues compared with the parrot feather plants.
\end{abstract}

Keywords: antibiotics; parrot feather; phytoremediation; water lettuce; water plants

\section{Introduction}

Phytoremediation is a technique that utilizes plants to remove or transform toxic chemicals incorporated in soils, ground water, and surface water. Various plants are used for removal or degradation of inorganic and organic contaminants, such as pesticides, antibiotics, heavy metals, and nutrients.

Phytoremediation techniques are used extensively because they have a number of advantages. Phytoremediation is low cost compared with conventional techniques and is suitable for treating very large land areas [1]. Furthermore, these techniques may be more effective than conventional techniques based on chemical extraction because the use of plants for environmental cleanup does not cause secondary pollution. However, phytoremediation also has limitations. A significant disadvantage of phytoremediation by aquatic plants is their shallow root systems, which limit the depth of soil treatment by the rhizosphere. Another disadvantage is the slow rate of environmental cleanup, which may take more than 10 years [2]. Phytoremediation effectiveness decreases during winter, and plant diseases or pests may occur in the condition of plant damage [3].

For decades, a wide variety of antibiotics has been extensively applied worldwide for preventing or treating human, animal, and plant infections and as feed additives for animals to prevent or treat diseases and promote growth [4]. Consumption of veterinary antibiotics has been increasing in both industrialized and developing countries. However, in Korea, the total production of antibiotics decreased significantly from 1500 tons in 2007 to 820 tons in 2013. This dramatic reduction in use of veterinary antibiotics was due to restrictions on their use for feed supplementation. Tetracyclines, sulfonamides, and penicillin are the most commonly used antibiotic types, with usage of 165, 60, and 160 tons, respectively, in 2014. These antibiotics are commonly found in both aquatic and agricultural 
environments, associated with the discharge of wastewater to the environment. Despite the low concentrations usually found in water ecosystems (from nanograms to micrograms per liter), continuous discharge of antibiotics and their degradation products through different pathways makes them 'pseudo-persistent' in the environment [5].

Macrophytes accumulate pollutants by incorporating them into the structures of their cells. In addition, these plants have a natural ability to absorb and metabolize xenobiotics while adapting to harsh conditions in a contaminated environment [6]. Some studies have used aqueous solution amended with different antibiotics to address plant uptake. The water plants Myriophyllum aquaticum (parrot feather) and Pistia stratiotes (water lettuce) were previously used for the study of phytoremediation of tetracyclines and oxytetracyclines in aqueous media [7]. Comparable levels of antibiotic removal by filtered root exudates from these two species a suggested involvement of root-secreted enzymes/metabolites in degrading/transforming the antibiotics [7].

The aim of the present study was to investigate the accumulation of antibiotics in two kinds of plants and to survey the phytotoxicity of antibiotics. The study was performed under hydroponic culture conditions to avoid potentially confounding effects of adsorption of antibiotics on soil particles [8]. The hydroponic culture solution contained a mixture of three commonly used antibiotics in South Korea: norfloxacin, sulfamethazine, and tetracyclines.

\section{Materials and Methods}

\subsection{Antibiotics and Chemicals}

Target antibiotic compounds were selected based on frequency of detection in the environment and physicochemical differences. In this study, tetracycline of the tetracycline type and sulfamethazine of the sulfonamide type, which are widely used in South Korea, were first selected as target antibiotics. In addition, norfloxacin, a quinolone type, was frequently detected in sewage wastewater and was additionally selected. We examined tetracyclines (TC), sulfamethazine (SMZ), and norfloxacin (NOR), which belong to three different antibiotic classes. All antibiotic standards and some internal standards were obtained from Sigma-Aldrich (St. Louis, MO, USA). All organic solvents used were HPLC grade and purchased from Merck Corporation (Darmstadt, Germany). Stock solutions and internal standards were prepared at $100 \mathrm{mg} / \mathrm{L}$ in methanol and stored in amber glass vials at $4{ }^{\circ} \mathrm{C}$.

\subsection{Experimental Design}

Selection of plants is important for achieving significant phytoremediation in aquatic ecosystems. The plants must be able to tolerate pollution and be easy to grow and fast growing. Prior to the experiments, 2 different types of water plants that have been used in wetland systems were cultured for 1 month in modified Hoagland's nutrient solution for acclimatization at a nearby plant nursery. We then obtained the plants and washed them to remove sediment particles. Identical plants were assigned to 9 glass containers, each containing 10 individuals arranged in parallel rows. We covered the surface of each container with silver foil to prevent the photodegradation of the antibiotics and to mitigate the effects of sunlight on the root systems. Throughout the study, hydroponic culture systems were supplied with 5 L Hoagland's nutrient solution fortified with the test antibiotics, the $\mathrm{pH}$ was adjusted to 6.5. The experiments took place in a greenhouse environment (12 h photoperiod, 30/25 $\pm 2{ }^{\circ} \mathrm{C}$ day/night), and all plants were treated for 30 days with the following concentrations of TC, SMZ, or NOR in nutrient solution: $0,1,5$, and $10 \mathrm{mg} / \mathrm{L}$. The Hoagland's nutrient solution was prepared as described by Dordio et al. [9]. The antibiotics in wastewater were frequently detected and ranged from ng/L up to lower $\mu \mathrm{g} / \mathrm{L}$ (norfloxacin: $2.775 \mu \mathrm{g} / \mathrm{L}$; sulfamethazine: $1.280 \mu \mathrm{g} / \mathrm{L}$; and tetracycline: $0.412 \mu \mathrm{g} / \mathrm{L}$; respectively) $[10,11]$. However, in this study, antibiotics were treated at relatively high concentrations to search for antibiotic hyperaccumulater water plants. We measured the following phytotoxicity parameters: leaf chlorophyll and fresh 
and dry weights of the water plants. At the end of the treatment period, samples of roots and shoots were obtained from the same pot. Roots were carefully washed in tap water. Plant materials were dried for 2 days at $60{ }^{\circ} \mathrm{C}$ and then frozen until analyzed. Control and treated plant materials were dried in separate drying ovens to prevent cross-contamination. The distributions of antibiotics in the hydroponic culture solution and water plants were analyzed.

\subsection{Assay of Phytotoxicity Parameters of Water Plants}

Chlorophyll contents ( $\mathrm{Chl} \mathrm{a,} \mathrm{Chl} \mathrm{b} \mathrm{and} \mathrm{total} \mathrm{Chl}$ ) of water plants were measured according to the method described by Huang et al. (2004) [12]. Plant leaves ( $0.2 \mathrm{~g} / 3$ parallel individuals in each container) were cut into $0.2 \mathrm{~cm}$ segments and treated in $80 \%(v / v)$ acetone for $24 \mathrm{~h}$ in the dark. Absorbance of the solutions was measured with a spectrophotometer (DR 5000, HACH, Loveland, CO, USA) at $663 \mathrm{~nm}$ and $645 \mathrm{~nm}$. After 30 days, the plants were harvested and washed with tap water and distilled water. Fresh weights of the plants were determined for each treatment, and dry weights of shoots and roots were determined after drying at $65^{\circ} \mathrm{C}$ for $48 \mathrm{~h}$.

\subsection{Antibiotic Analysis in Water and Plant Samples}

Liquid chromatography in combination with tandem mass spectrometry (LC-MS/MS) was used to analyze the antibiotics in the plant and water samples. Prior to extraction, the water was filtered through Whatman no. 1 filter paper to eliminate the suspended matter and then filtered through a $0.45 \mu \mathrm{m}$ mixed cellulose membrane. The $\mathrm{pH}$ of water samples was adjusted to 4.0 with $1 \mathrm{~mol} / \mathrm{L} \mathrm{H}_{2} \mathrm{SO}_{4}$. The antibiotics were extracted in $250 \mathrm{~mL}$ of filtered water. The plant samples were freeze-dried and ground to 80 mesh. A mixed solution $(5 \mathrm{~mL})$ containing phosphate buffer, acetonitrile, and the plant samples was added to each centrifuge tube. The tubes were shaken in a shaker at $250 \mathrm{rpm}$ for $30 \mathrm{~min}$, sonicated for $10 \mathrm{~min}$, and then centrifuged at $12,000 \times \mathrm{g}$ for $10 \mathrm{~min}$.

The extraction process was performed 3 times for each sample. The samples were extracted using Oasis HLB extraction cartridges (500 mg, 6 mL, Waters, Milford, MA, USA) in the following manner. Each cartridge was sequentially pre-conditioned with $6.0 \mathrm{~mL}$ acetone, $6.0 \mathrm{~mL}$ methanol, and $6.0 \mathrm{~mL} 0.1 \%$ formic acid solution. The samples were passed through an extraction cartridge at a rate of $3 \mathrm{~mL} / \mathrm{min}$. Subsequently, the cartridge was rinsed with $5 \mathrm{~mL} 0.1 \%$ formic acid solution containing $5 \mathrm{mmol} / \mathrm{L}$ ammonium acetate and then eluted with $5.0 \mathrm{~mL}$ methanol. Finally, the target fraction was re-dissolved in $10 \%$ methanol solution to a final volume of $1.0 \mathrm{~mL}$ for LC-MS/MS (ABI 3200 Q TRAP) analysis. The antibiotics were analyzed using a LC-MS/MS system with an Inertsil ${ }^{\circledR}$ ODS-SP column for separation. The chromatographic mobile phase consisted of methanol (A) and $0.1 \%$ formic acid solution dissolved with $5 \mathrm{mmol} / \mathrm{L}$ ammonium acetate (B). The column temperature was set to $40^{\circ} \mathrm{C}$. The target antibiotics were detected by electrospray tandem mass spectrometry in positive-ion mode. Data acquisition was performed by multiple reaction monitoring (MRM), recording two MRM sessions per compound. The optimal conditions are summarized in Table 1 . The correlation coefficients $\left(R^{2}\right)$ of the calibration curves exceeded 0.99 for all analytes. Recoveries of the antibiotics in the plant and water samples were determined at different concentrations in triplicate and calculated as percentages of the measured concentration, relative to the spiked concentration. Limits of quantification (LOQ) of the antibiotics were calculated with signal-noise ratios of 10 . Retention time, correlation coefficient, LOQ, and recovery of the samples are summarized in Table 2. 
Table 1. Optimum LC-MS/MS parameters of precursor and product ions and collision energy (CE).

\begin{tabular}{cccc}
\hline Antibiotics & Precursor Ion $(\mathbf{m} / \mathbf{z})$ & Product Ion $(\mathbf{m} / \mathbf{z})$ & Collision Energy $(\mathbf{e V})$ \\
\hline NOR & 152 & 110.0 & 16 \\
\hline TC & 445 & 410.0 & 25 \\
\hline SMZ & 279 & 186.1 & 24 \\
\hline
\end{tabular}

NOR—norfloxacin; SMZ—sulfamethazine; TC—-tetracycline.

Table 2. Retention time, correlation coefficient, recovery, and limit of quantification (LOQ) of samples.

\begin{tabular}{cccccc}
\hline \multirow{2}{*}{ Antibiotics } & \multirow{2}{*}{ Retention Time } & \multirow{2}{*}{$\mathbf{R}^{\mathbf{2}}$} & LOQ (ng/g) & \multicolumn{2}{c}{ Recovery (\%) } \\
\cline { 5 - 6 } & & & & Plant & Water \\
\hline NOR & 3.52 & 0.99 & 2.59 & $80.1 \pm 2.8$ & $91.2 \pm 3.2$ \\
\hline TC & 7.49 & 0.99 & 5.17 & $74.1 \pm 3.6$ & $84.6 \pm 2.0$ \\
\hline SMZ & 7.68 & 0.99 & 1.54 & $79.9 \pm 2.2$ & $88.7 \pm 3.2$ \\
\hline
\end{tabular}

\subsection{Bioconcentration Factor}

To evaluate the abilities of the two water plant species to extract and accumulate antibiotics into plant tissues, the bioconcentration factor (BCF) was determined for roots, according to the method described by Zayed et al. [13], as follows:

$$
\mathrm{BCF}=\frac{\text { Pollutant concentration in plant tissue at harvest }(\mathrm{mg} / \mathrm{kg})}{\text { Initial concentration in the external growth medium }\left(\frac{\mathrm{mg}}{\mathrm{L}}\right)}
$$

\section{Results and Discussion}

\subsection{Effects of Antibiotics on Growth of Water Plants}

The objective of this study was to identify water plant species capable of efficient removal of antibiotics from aquatic environments without adverse effects on their growth and morphology. During the 30-day experimental period using 1-5 ppm treatment concentrations, we noticed no visible signs of detrimental effects or yellow leaves in either species. The growth of plants in the hydroponic culture solution was good, as demonstrated by significantly greater biomass yield at the end than at the beginning of the experiment (Figure 1). By the 10th day of the experiment, the containers were completely covered by plants. However, at $10 \mathrm{ppm}$ treatment concentrations, plant growth was inhibited by $40-50 \%$. In particular, we observed chlorosis and early abscission of leaves. Neither water lettuce nor parrot feather plants showed difference in fresh plant weight according to type of antibiotic used. The fresh weight of plants decreased in a concentration-dependent manner as antibiotic concentration increased (Figure 2).
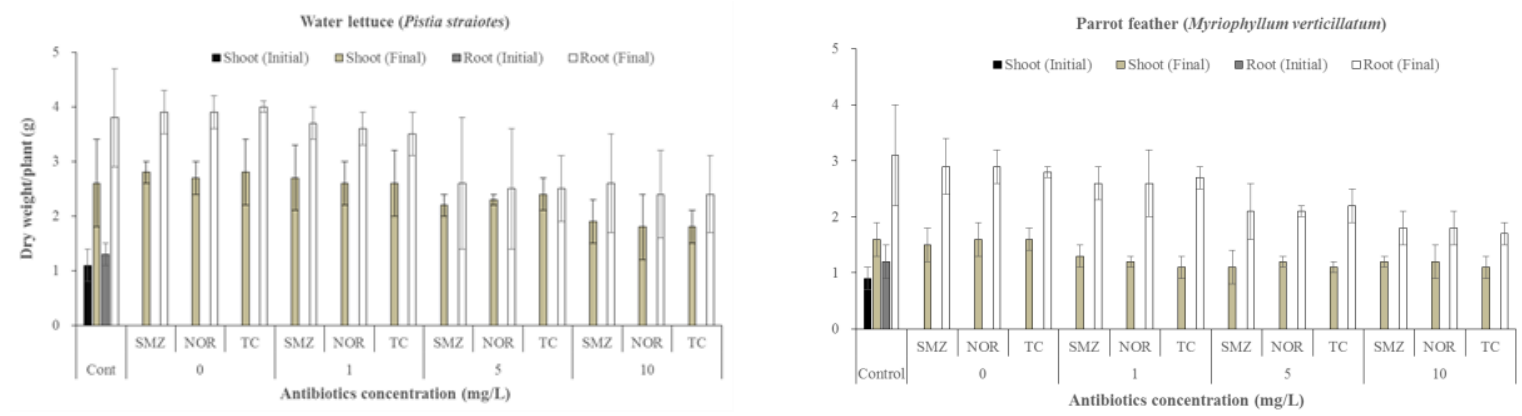

Figure 1. Dry weights of water lettuce and parrot feather under various treatments at the end of the experimental period. 

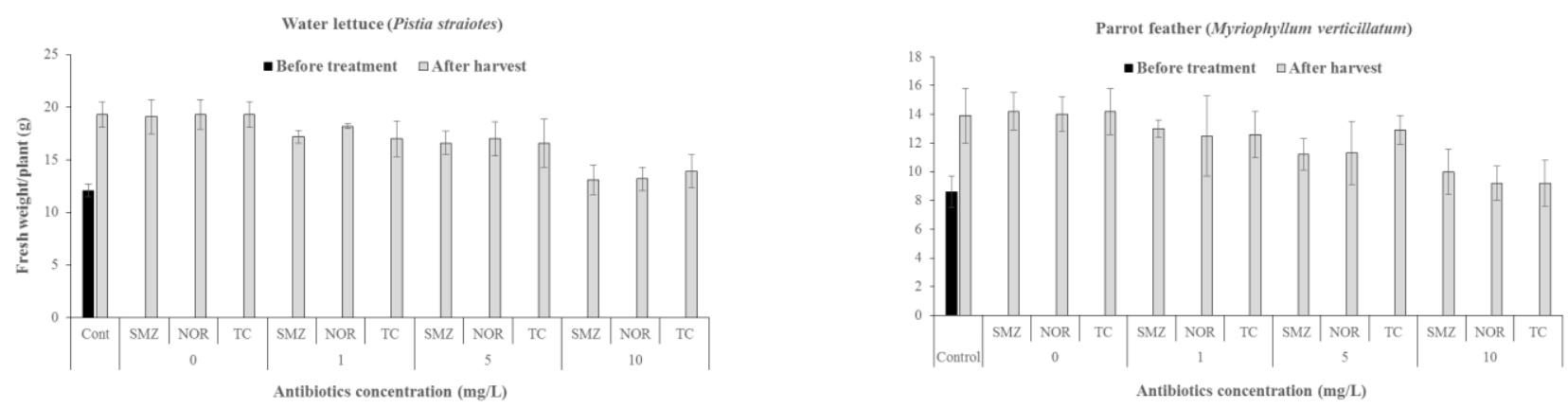

Figure 2. Fresh weights of water lettuce and parrot feather plants under various treatments at the end of the experimental period.

\subsection{Effects of Antibiotics on Chlorophyll Content}

Plant chlorophyll content is an important parameter for evaluating photosynthetic activity, and such measurements can be used as indicators of pollutant-induced plant stress [12]. Plant total chlorophyll, chlorophyll $\mathrm{a}$, and chlorophyll b were all affected by antibiotic treatment. At the end of the treatment period, inhibition rates of total chlorophyll content of the 2 water plants for control, $1 \mathrm{ppm}, 5 \mathrm{ppm}$, and $10 \mathrm{ppm}$ treatments were $3.1-5.9 \%, 13.3-16.8 \%, 33.9-44.2 \%$, and $41.5-45.2 \%$, respectively (Tables 3 and 4). Antibiotics administered at concentrations greater than $5 \mathrm{mg} / \mathrm{L}$ seriously disrupted the normal chlorophyll content of water lettuce and parrot feather plants. The inhibition rate of chlorophyll b was higher than that of chlorophyll after antibiotic treatment. Plant total chlorophyll, chlorophyll $\mathrm{a}$, and chlorophyll $\mathrm{b}$ did not significantly differ between the water lettuce and parrot feather plants. The inhibition rates of chlorophyll in water plants increased as antibiotic concentrations increased, possibly because organic pollutants block electron transport flow from photosystem II to photosystem I, thereby inhibiting plant biosynthesis of chlorophyll b [11].

\subsection{Antibiotic Residues in Aqueous Solution}

Antibiotic concentrations in hydroponic culture solution under various treatment concentrations during the experiment period are shown in Figures 3 and 4. In water lettuce plants, SMZ and TC were lower than the limit of detection in aqueous solution from 21 days after treatment. However, $60 \%$ of the treated amount of NOR remained in aqueous solution. The water solubilities of treated antibiotics were SMZ $1500 \mathrm{mg} / \mathrm{L}$ $\mathrm{H}_{2} \mathrm{O}\left(25^{\circ} \mathrm{C}\right)$, TC $231 \mathrm{mg} / \mathrm{L} \mathrm{H}_{2} \mathrm{O}\left(25^{\circ} \mathrm{C}\right)$, and NOR $0.28 \mathrm{mg} / \mathrm{mL} \mathrm{H}_{2} \mathrm{O}\left(25^{\circ} \mathrm{C}\right)$. The high residual amount of NOR in aqueous solution is presumably due to water solubility. It was previously reported that absorption, abiotic transformation, and biotic transformation are major processes that antibiotics undergo in aquatic environments [14]. Hydrolysis and biodegradation also comprise an important degradation pathway for organic pollutants in aquatic ecosystem. In the present study, treated water plants showed greater removal efficiency of antibiotics compared with the control group (data not shown). We conclude that water plants play an important role in reduction in antibiotic contamination in aquatic environments, especially SMZ and TC. Parrot feather plants showed similar trends to water lettuce plants. 


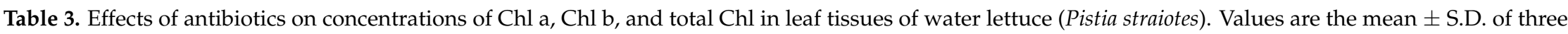
parallel individuals in each container, with three measurements from each sample.

\begin{tabular}{|c|c|c|c|c|c|c|c|c|c|c|c|c|c|}
\hline \multirow{3}{*}{ Item } & \multirow{3}{*}{ DAT } & \multicolumn{12}{|c|}{ Inhibition Rates of Chlorophyll (\%) } \\
\hline & & \multicolumn{3}{|c|}{0} & \multicolumn{3}{|c|}{$1 \mathrm{mg} / \mathrm{L}$} & \multicolumn{3}{|c|}{$5 \mathrm{mg} / \mathrm{L}$} & \multicolumn{3}{|c|}{$10 \mathrm{mg} / \mathrm{L}$} \\
\hline & & SMZ & NOR & TC & SMZ & NOR & TC & SMZ & NOR & TC & SMZ & NOR & TC \\
\hline \multirow{6}{*}{ Chl a } & 1 & 0 & 0 & 0 & 0 & 0 & 0 & 0 & 0 & 0 & 0 & 0 & 0 \\
\hline & 3 & 0 & 0 & 0 & 0 & 0 & 0 & 0 & $-3.1 \pm 0.1$ & $-1.8 \pm 0.2$ & 0 & -10 & -9 \\
\hline & 7 & 0 & 0 & 0 & $-6.9 \pm 0.6$ & $-3.0 \pm 0.1$ & $-1.2 \pm 0.1$ & $-6.5 \pm 0.3$ & $-10.5 \pm 0.6$ & $-12.9 \pm 0.3$ & $-21.3 \pm 3.1$ & $-24.4 \pm 3.1$ & $-32.9 \pm 1.4$ \\
\hline & 14 & $-3.8 \pm 0.2$ & $-2.2 \pm 0.1$ & $-1.6 \pm 0.2$ & $-8.5 \pm 0.4$ & $-3.3 \pm 0.2$ & $-6.5 \pm 0.2$ & $-15.5 \pm 1.1$ & $-15.3 \pm 1.5$ & $-10.3 \pm 1.1$ & $-30.0 \pm 2.0$ & $-32.5 \pm 2.9$ & $-39.8 \pm 2.0$ \\
\hline & 21 & $-3.9 \pm 0.5$ & $-3.8 \pm 0.4$ & $-3.7 \pm 0.3$ & $-13.1 \pm 0.9$ & $-8.2 \pm 0.6$ & $-6.0 \pm 0.6$ & $-25.6 \pm 5.6$ & $-16.3 \pm 1.1$ & $-16.6 \pm 2.0$ & $-35.3 \pm 3.1$ & $-30.1 \pm 6.9$ & $-42.2 \pm 1.3$ \\
\hline & 30 & $-4.6 \pm 0.3$ & $-2.6 \pm 0.3$ & $-3.2 \pm 0.3$ & $-15.3 \pm 1.2$ & $-10.1 \pm 1.9$ & $-14.9 \pm 1.9$ & $-31.3 \pm 6.2$ & $-26.1 \pm 5.6$ & $-31.6 \pm 2.3$ & $-42.9 \pm 3.9$ & $-43.6 \pm 3.4$ & $-50.4 \pm 3.5$ \\
\hline \multirow{6}{*}{ Chl b } & 1 & 0 & 0 & 0 & 0 & 0 & 0 & 0 & 0 & 0 & 0 & 0 & 0 \\
\hline & 3 & 0 & 0 & 0 & $-1.9 \pm 0.3$ & $-3.0 \pm 0.3$ & $-3.4 \pm 0.3$ & $-2.3 \pm 0.1$ & $-3.8 \pm 0.9$ & $-3.2 \pm 0.2$ & $-4.2 \pm 0.2$ & $-5.2 \pm 0.3$ & $-5.3 \pm 0.4$ \\
\hline & 7 & 0 & 0 & 0 & $-9.6 \pm 0.6$ & $-8.9 \pm 1.2$ & $-9.3 \pm 0.3$ & $-14.9 \pm 2.5$ & $-19.8 \pm 1.1$ & $-16.5 \pm 1.5$ & $-20.3 \pm 1.4$ & $-16.4 \pm 0.9$ & $-14.4 \pm 1.0$ \\
\hline & 14 & $-1.2 \pm 0.1$ & 0 & 0 & $-11.4 \pm 0.2$ & $-15.2 \pm 1.9$ & $-16.3 \pm 1.0$ & $-32.4 \pm 3.5$ & $-25.3 \pm 2.5$ & $-29.9 \pm 3.2$ & $-33.4 \pm 1.2$ & $-31.6 \pm 1.2$ & $-22.1 \pm 0.6$ \\
\hline & 21 & $-2.3 \pm 0.1$ & $-2.2 \pm 0.1$ & $-3.8 \pm 0.1$ & $-25.6 \pm 0.9$ & $-21.3 \pm 3.6$ & $-18.8 \pm 1.9$ & $-36.0 \pm 5.2$ & $-29.1 \pm 3.3$ & $-33.3 \pm 3.0$ & $-36.8 \pm 2.2$ & $-32.0 \pm 2.9$ & $-30.9 \pm 2.9$ \\
\hline & 30 & $-3.7 \pm 0.2$ & $-3.7 \pm 0.4$ & $-4.3 \pm 0.3$ & $-26.2 \pm 0.5$ & $-22.5 \pm 4.1$ & $-21.6 \pm 3.5$ & $-41.3 \pm 5.1$ & $-32.5 \pm 3.6$ & $-39.8 \pm 4.2$ & $-36.9 \pm 2.5$ & $-34.1 \pm 3.3$ & $-33.2 \pm 3.6$ \\
\hline \multirow{5}{*}{ Tot Chl } & 3 & 0 & 0 & 0 & 0 & 0 & 0 & $-2.2 \pm 0.1$ & $-3.9 \pm 0.6$ & $-3.3 \pm 1.0$ & $-3.3 \pm 0.6$ & $-4.3 \pm 0.1$ & $-4.1 \pm 0.2$ \\
\hline & 7 & 0 & 0 & 0 & $-5.4 \pm 0.4$ & $-6.1 \pm 0.3$ & $-5.1 \pm 0.1$ & $-5.6 \pm 0.1$ & $-12.1 \pm 0.1$ & $-9.8 \pm 0.3$ & $-18.2 \pm 0.9$ & $-26.3 \pm 0.9$ & $-29.6 \pm 0.9$ \\
\hline & 14 & 0 & $-1.3 \pm 0.2$ & $-1.1 \pm 0.1$ & $-9.3 \pm 0.2$ & $-12.9 \pm 0.3$ & $-11.1 \pm 0.6$ & $-24.6 \pm 0.6$ & $-21.3 \pm 3.3$ & $-20.2 \pm 1.3$ & $-26.1 \pm 1.5$ & $-30.9 \pm 0.6$ & $-28.2 \pm 0.3$ \\
\hline & 21 & $-3.4 \pm 0.2$ & $-3.2 \pm 0.2$ & $-4.3 \pm 0.2$ & $-13.9 \pm 1.3$ & $-13.3 \pm 0.9$ & $-12.9 \pm 0.2$ & $-29.1 \pm 0.9$ & $-25.5 \pm 3.6$ & $-26.6 \pm 1.3$ & $-41.6 \pm 1.9$ & $-38.2 \pm 1.5$ & $-33.6 \pm 1.9$ \\
\hline & 30 & $-3.6 \pm 0.5$ & $-3.1 \pm 0.1$ & $-5.2 \pm 0.5$ & $-16.8 \pm 1.0$ & $-15.5 \pm 1.9$ & $-16.3 \pm 0.5$ & $-36.1 \pm 0.2$ & $-35.6 \pm 5.2$ & $-39.5 \pm 3.0$ & $-42.2 \pm 1.8$ & $-42.6 \pm 2.9$ & $-45.2 \pm 2.1$ \\
\hline
\end{tabular}




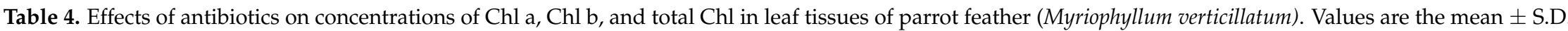
of three parallel individuals in each container, with three measurements from each sample.

\begin{tabular}{|c|c|c|c|c|c|c|c|c|c|c|c|c|c|}
\hline \multirow{3}{*}{ Item } & \multirow{3}{*}{ DAT } & \multicolumn{12}{|c|}{ Inhibition Rates of Chlorophyll (\%) } \\
\hline & & \multicolumn{3}{|c|}{0} & \multicolumn{3}{|c|}{$1 \mathrm{mg} / \mathrm{L}$} & \multicolumn{3}{|c|}{$5 \mathrm{mg} / \mathrm{L}$} & \multicolumn{3}{|c|}{$10 \mathrm{mg} / \mathrm{L}$} \\
\hline & & SMZ & NOR & TC & SMZ & NOR & TC & SMZ & NOR & TC & SMZ & NOR & TC \\
\hline \multirow{6}{*}{ Chl a } & 1 & 0 & 0 & 0 & 0 & 0 & 0 & 0 & 0 & 0 & 0 & 0 & 0 \\
\hline & 3 & 0 & 0 & 0 & 0 & 0 & 0 & 0 & $-1.0 \pm 0.2$ & $-1.1 \pm 0.1$ & $-1.9 \pm 0.3$ & $-3.7 \pm 0.1$ & $-3.1 \pm 0.1$ \\
\hline & 7 & 0 & 0 & 0 & $-2.1 \pm 0.1$ & $-2.3 \pm 0.4$ & $-1.6 \pm 0.2$ & $-2.9 \pm 0.1$ & $-9.3 \pm 0.4$ & $-3.2 \pm 0.1$ & $-5.5 \pm 1.1$ & $-20.5 \pm 1.1$ & $-26.1 \pm 2.9$ \\
\hline & 14 & $-1.2 \pm 0.1$ & $-1.6 \pm 0.1$ & $-1.1 \pm 0.1$ & $-3.9 \pm 0.2$ & $-5.1 \pm 0.1$ & $-5.3 \pm 0.3$ & $-9.3 \pm 0.6$ & $-11.4 \pm 0.9$ & $-9.8 \pm 0.2$ & $-11.4 \pm 1.3$ & $-24.4 \pm 1.9$ & $-26.9 \pm 3.9$ \\
\hline & 21 & $-3.0 \pm 0.3$ & $-3.1 \pm 0.1$ & $-3.2 \pm 0.1$ & $-7.4 \pm 0.3$ & $-11.6 \pm 0.9$ & $-7.2 \pm 0.1$ & $-13.2 \pm 2.3$ & $-19.1 \pm 1.3$ & $-19.3 \pm 0.6$ & $-18.9 \pm 2.6$ & $-29.6 \pm 2.6$ & $-31.2 \pm 2.5$ \\
\hline & 30 & $-4.1 \pm 0.9$ & $-3.2 \pm 0.2$ & $-4.3 \pm 0.2$ & $-9.5 \pm 0.9$ & $-15.9 \pm 1.2$ & $-13.3 \pm 0.6$ & $-19.9 \pm 1.9$ & $-26.0 \pm 3.4$ & $-26.4 \pm 1.9$ & $-29.6 \pm 2.9$ & $-32.5 \pm 2.5$ & $-34.9 \pm 3.4$ \\
\hline \multirow{6}{*}{ Chl b } & 1 & 0 & 0 & 0 & 0 & 0 & 0 & 0 & 0 & 0 & 0 & 0 & 0 \\
\hline & 3 & 0 & 0 & 0 & 0 & 0 & $-2.2 \pm 0.1$ & $-1.1 \pm 0.2$ & $-2.1 \pm 0.2$ & $-2.1 \pm 0.1$ & $-6.5 \pm 0.1$ & $-4.1 \pm 0.9$ & $-6.6 \pm 0.2$ \\
\hline & 7 & 0 & 0 & 0 & $-2.1 \pm 0.6$ & $-3.6 \pm 0.4$ & $-6.0 \pm 0.5$ & $-3.2 \pm 0.5$ & $-12.9 \pm 0.5$ & $-15.9 \pm 2.2$ & $-16.2 \pm 0.3$ & $-16.0 \pm 1.1$ & $-10.1 \pm 1.8$ \\
\hline & 14 & 0 & 0 & 0 & $-6.3 \pm 0.2$ & $-10.1 \pm 1.2$ & $-10.1 \pm 0.2$ & $-19.6 \pm 1.1$ & $-21.4 \pm 0.9$ & $-19.1 \pm 2.1$ & $-29.9 \pm 0.9$ & $-30.9 \pm 1.9$ & $-20.9 \pm 1.1$ \\
\hline & 21 & 0 & $-2.5 \pm 0.2$ & $-4.6 \pm 0.6$ & $-9.1 \pm 0.9$ & $-19.9 \pm 3.0$ & $-13.6 \pm 1.2$ & $-30.2 \pm 1.9$ & $-41.2 \pm 2.9$ & $-32.2 \pm 1.5$ & $-29.1 \pm 1.1$ & $-39.2 \pm 2.1$ & $-41.2 \pm 2.0$ \\
\hline & 30 & 0 & $-1.3 \pm 0.1$ & $-2.1 \pm 0.1$ & $-19.9 \pm 0.5$ & $-26.3 \pm 2.9$ & $-20.1 \pm 2.1$ & $-36.6 \pm 3.2$ & $-45.9 \pm 4.1$ & $-29.1 \pm 2.9$ & $-42.0 \pm 1.9$ & $-39.8 \pm 2.5$ & $-41.0 \pm 2.9$ \\
\hline \multirow{5}{*}{ Tot Chl } & 3 & 0 & 0 & 0 & 0 & 0 & 0 & $-2.9 \pm 0.1$ & $-3.1 \pm 0.2$ & $-3.0 \pm 0.1$ & $-3.1 \pm 0.1$ & $-3.6 \pm 0.6$ & $-4.9 \pm 0.4$ \\
\hline & 7 & 0 & 0 & 0 & $-5.0 \pm 0.3$ & $-6.0 \pm 0.1$ & $-5.9 \pm 0.3$ & $-5.2 \pm 0.3$ & $-12.9 \pm 0.9$ & $-8.1 \pm 0.6$ & $-17.1 \pm 0.3$ & $-25.4 \pm 1.8$ & $-23.5 \pm 0.2$ \\
\hline & 14 & 0 & $-1.1 \pm 0.1$ & $-1.5 \pm 0.2$ & $-9.2 \pm 0.1$ & $-12.1 \pm 0.2$ & $-12.2 \pm 0.5$ & $-23.1 \pm 0.2$ & $-30.1 \pm 1.5$ & $-21.4 \pm 0.6$ & $-23.2 \pm 2.1$ & $-31.2 \pm 2.9$ & $-29.7 \pm 3.2$ \\
\hline & 21 & $-3.9 \pm 0.6$ & $-3.3 \pm 0.5$ & $-4.4 \pm 0.3$ & $-13.1 \pm 0.6$ & $-12.6 \pm 0.9$ & $-13.0 \pm 0.5$ & $-29.9 \pm 1.5$ & $-33.1 \pm 2.6$ & $-25.6 \pm 3.5$ & $-40.9 \pm 3.3$ & $-37.1 \pm 2.2$ & $-30.3 \pm 2.1$ \\
\hline & 30 & $-3.3 \pm 0.2$ & $-3.9 \pm 0.2$ & $-5.9 \pm 0.2$ & $-14.1 \pm 0.5$ & $-13.3 \pm 2.1$ & $-16.1 \pm 0.9$ & $-44.2 \pm 1.3$ & $-33.9 \pm 3.8$ & $-41.1 \pm 2.9$ & $-41.5 \pm 2.9$ & $-42.5 \pm 4.2$ & $-42.9 \pm 4.3$ \\
\hline
\end{tabular}



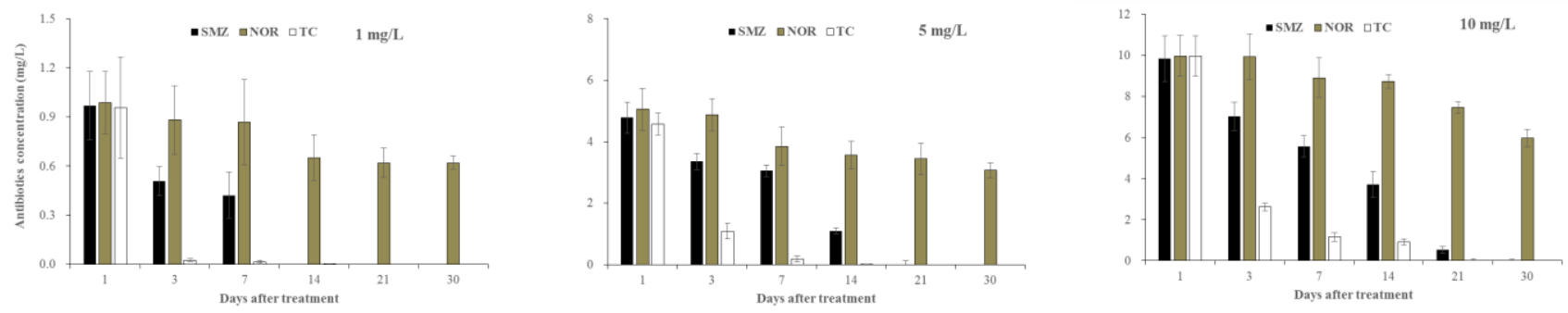

Figure 3. Selected antibiotic concentrations in hydroponic culture solution (water lettuce) under various treatments at the end of the experimental period.
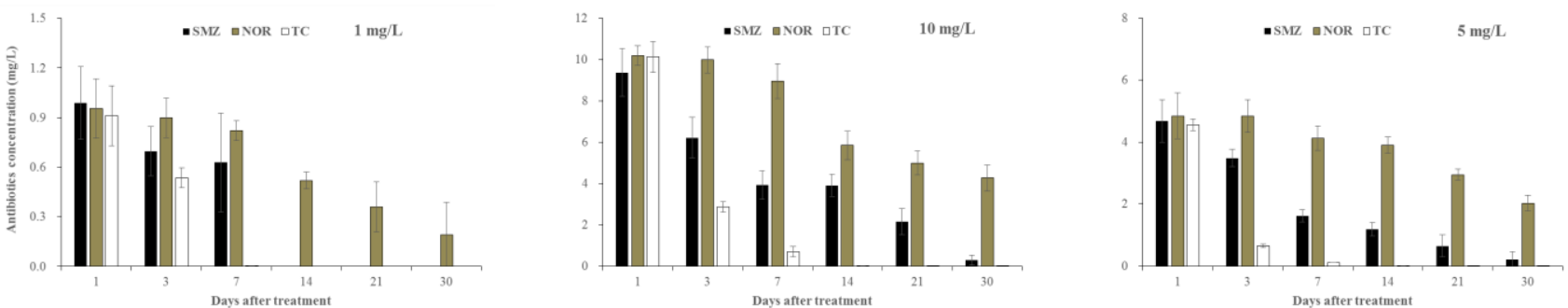

Figure 4. Selected antibiotic concentrations in hydroponic culture solution (parrot feather) under various under various treatments at the end of the experimental period.

\subsection{Uptake Translocation of Antibiotics into Water Lettuce and Parrot Feather}

In the harvest stage of the plant, we analyzed the SMZ, NOR, and TC contents of water lettuce and parrot feather. The results clearly indicated that the three antibiotics were taken up by both plants. Further, the uptake translocation of antibiotics was positively correlated with antibiotic concentration, a finding that is similar to those of previous studies $[15,16]$. None of the three antibiotics were detected in the shoots of the water lettuce plants, only in the root. However, in the parrot feather plants, antibiotics were detected in both the shoots and the roots, with higher amounts detected in the shoots than in the roots. Most SMZ and TC were detected in the roots and shoots of the water lettuce and parrot feather plants, and about one-third of the treated amount of NOR was detected (Figure 5). The low NOR uptake by plants is associated with water solubility. In this study, we found that the uptake translocation mechanisms of parrot feather differed from those of water lettuce. The antibiotics were taken up and transported via mass flow and active transport [15]. In general, there is a close correlation between antibiotic uptake translocation into plants and the antibiotic octanol/water partition coefficient (log $\left.\mathrm{K}_{\mathrm{OW}}\right)$. There is an optimal hydrophobicity value for antibiotic uptake translocation, and that organic compounds that are either highly polar $\left(\log \mathrm{K}_{\mathrm{OW}}<1\right)$ or highly lipophilic $\left(\log K_{\mathrm{OW}}>4\right)$ will not be significantly taken up by plants $[15,17]$. In this study, $\log \mathrm{K}_{\mathrm{OW}}$ values for SMZ, NOR, and TC were below 0.5. Further, we conducted experiments in a plastic film house environment at a temperature of $30 / 25 \pm 2{ }^{\circ} \mathrm{C}$ day/night, and the volume of evapotranspiration water in all treatments was greater than $160-170 \mathrm{~mL} /$ day. Therefore, we hypothesized that antibiotics were taken up through mass flow and passive absorption. SMZ, NOR, and TC accumulated at different levels in water plants, likely because of their different solubilities, affinities, and absorption mechanisms. Specifically, the solubility value of SMZ was much higher than those of NOR and TC. Dettenmaier et al. [18] indicated that highly water soluble organic compounds are most likely to be taken up by plants. The three antibiotics were detected in shoots and roots, but there were different distributions for different antibiotics. The plant root was the primary point of contact with antibiotic solution; thus, most antibiotics accumulated in the root system via biological and physical-chemical uptake. Removal of antibiotics from hydroponic culture solution takes place through a variety of mechanisms, namely hydrolysis, biodegradation, 
photodegradation, and plant uptake. In hydrosphere ecosystems, further research is needed to investigate the mechanism of phytoremediation of antibiotics by aquatic plants.
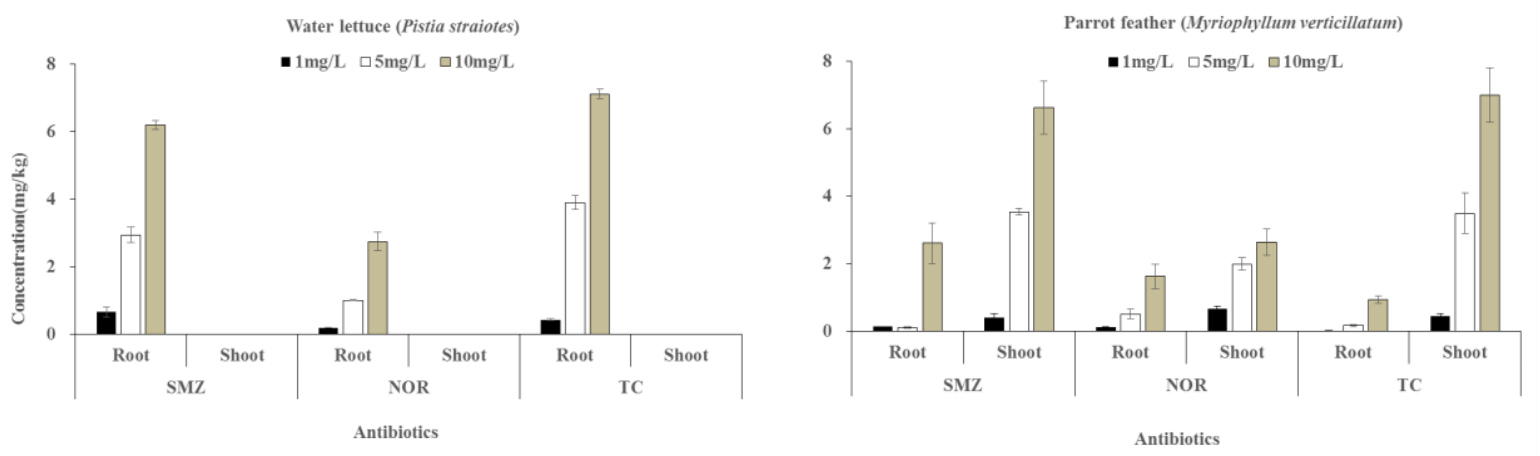

Figure 5. Selected antibiotic concentrations (on a dry weight basis) in water lettuce and parrot feather plants under various treatments at the end of the experimental period. Values are the mean \pm S.D. of three parallel individuals in each container.

\subsection{Bioconcentration Factor}

Plants having both phytostabilization and pollution-tolerant capacities are potentially useful for phytoremediation purposes. The mean BCF values for antibiotics in water lettuce and parrot feather tissues are shown in Figure 6. Uptake translocation of antibiotics varied among treatments. In water lettuce tissues, BCF of antibiotics ranged from 0.24 to 0.78 , while that of NOR was much lower, ranging from 0.24 to 0.38 . In addition, SMZ (0.59-0.64) and TET (0.72-0.78) showed higher uptake accumulation into water lettuce tissues. The $\mathrm{BCF}$ values of water lettuce and parrot feather showed similar trends but were higher for parrot feather (Figure 6). The differences in uptake accumulation of antibiotics in water plants are governed by antibiotic concentrations, crop species, and environmental conditions. SMZ and TC showed $60-80 \%$ removal, in the range of $1-10 \mathrm{mg} / \mathrm{L}$ of treatment concentration, but NOR removed only $20-30 \%$. Parrot feather was slightly more effective in this respect than water lettuce. BCF values greater than 1 are generally believed to indicate the potential success of a plant species for phytoremediation. The BCF values of inorganic metal ions are often higher than 1 [19]; however, in this study, BCF values of antibiotics, which are toxic organic substances, were less than 1 . The BCF values of antibiotics were similar to those measured in previous studies [18]. In this study, the metabolites of the three antibiotics could not be identified due to various research limitations. We present data for estimating metabolites of three antibiotics using previous research data. Biotransformation was shown to be the main removal process for the parent antibiotics from the aqueous phase and abiotic transformation, mineralization, and sorption to the suspended solids [20]. Microbacterium sp. strain 4N2-2 produces four metabolites (8-hydroxynorfloxacin, 6-defluoro-6-hydroxynorfloxacin, desethylene-norfloxacin, and $\mathrm{N}$-acetylnorfloxacin) from norfloxacin [21], Streptomyces sp. strain AL-16012 produces five metabolites (chlorotetracycline, doxytetracycline, meclotetracycine, minotetracycline, and rolitetracycline) from tetracycline [20], and ammonia-oxidizing archaeon strain produces two metabolites (acetyl + hydroxy (AcOH-sulfonamide) and N4-formyl-sulfonamide) from sulfamethazine [22] through glycosylation, decarboxylation, hydroxylation, oxidative defluorination, desethylation, and $\mathrm{N}$-acetylation. These metabolites, of course, may be subjected to further degradation by other environmental microorganisms. Three antibiotic types - quinolones, sulfonamides, and tetracyclines - which are thought to be genetically toxic to fishes, have been reported to bioaccumulate in fish tissues, as well as in aquatic environments, such as rivers and surface water. The adverse effects of these antibiotics are known to cause damage to developmental, cardiovascular, and metabolic systems, as well as in altering antioxidant and immune responses, in fishes. Therefore, there are continuous concerns about the toxicity of antibiotics in fishes and management strategies are needed [20-22]. 

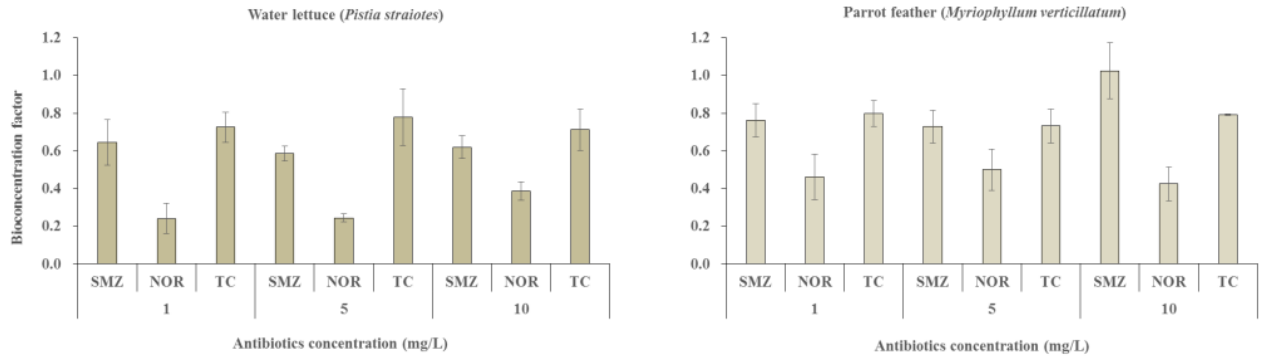

Figure 6. Bioconcentration factor $(\mathrm{BCF})$ values of antibiotics in water lettuce and parrot feather plants (mean $\pm \mathrm{SD}, \mathrm{n}=3$ ).

Author Contributions: Y.-J.P. and J.-G.S. performed the experiments and wrote the article. All authors have read and agreed to the published version of the manuscript.

Funding: This paper was supported by research funds of Jeonbuk National University in 2019.

Institutional Review Board Statement: Not applicable.

Informed Consent Statement: Not applicable.

Data Availability Statement: The data used in this study can be available from the authors on reasonable request.

Conflicts of Interest: The authors declare no conflict of interest.

\section{References}

1. Garbisu, C.; Alkorta, I. Phytoextraction: A cost-effective plant-based technology for the removal of metals from the environment. Bioresour. Technol. 2001, 77, 229-236. [CrossRef]

2. Paz-Alberto, A.M. Phytoremediation: A green technology to remove environmental pollutants. Am. J. Clim. Chang. 2013, 2, 71-86. [CrossRef]

3. Milena, M.; Anna, W.; Elbieta, S. Phytoremediation techniques in wastewater treatment. Environ. Biotechnol. $2015,11,10-13$.

4. Du, L.F.; Liu, W.K. Occurrence, fate, and ecotoxicity of antibiotics in agroecosystems: A review. Agron. Sustain. Dev. 2012, 32, 309-327. [CrossRef]

5. Grassi, M.; Luigi, R.; Anna, F. Endocrine disruptors compounds, pharmaceuticals and personal care products in urban wastewater: Implications for agricultural reuse and their removal by adsorption process. Environ. Sci. Pollut. Res. 2013, 20, 3618-3628. [CrossRef] [PubMed]

6. Tasho, R.P.; Cho, J.Y. Veterinary antibiotics in animal waste, its distribution in soil and uptake by plants: A review. Sci. Total Environ. 2016, 563, 366-376. [CrossRef]

7. Gujarathi, N.P.; Bryan, J.H.; James, C.L. Phytoremediation potential of Myriophyllum aquaticum and Pistia stratiotes to modify antibiotic growth promoters, tetracycline, and oxytetracycline, in aqueous wastewater systems. Int. J. Phytoremediat. 2015, 7 , 99-112. [CrossRef] [PubMed]

8. Hillis, D.G.; Fletcher, J.; Solomon, K.R.; Sibley, P.K. Effects of ten antibiotics on seed germination and root elongation in three plant species. Arch. Environ. Contam. Toxicol. 2011, 60, 220-232. [CrossRef]

9. Dordio, A.V.; Duarte, C.; Barreiros, M.; Carvalho, A.; Pinto, A.; Costa, C.T. Toxicity and removal efficiency of pharmaceutical metabolite clofibric acid by Typha spp. Bioresour. Technol. 2009, 100, 1156-1161. [CrossRef] [PubMed]

10. Ghosh, G.C.; Hanamoto, S.; Yamashita, N.; Huang, X.; Tanaka, H. Antibiotics removal in biological sewage treatment plants. Pollution 2016, 2, 131-139.

11. Jathwa, A.I.; Muna, Y.A.A. Detection of tetracycline, doxycycline, chlortetracycline, and oxytetracycline antibiotics in Nineveha drug wastewater. Al-Nahrain J. Eng. Sci. 2012, 15, 215-221.

12. Huang, X.D.; El-Alawi, Y.; Penrose, D.M.; Glick, B.R.; Greenberg, B.M. Responses of three grass species to creosote during phytoremediation. Environ. Pollut. 2004, 130, 453-463. [CrossRef]

13. Zayed, A.; Gowthaman, S.; Terry, N. Phytoaccumulation of trace elements by wetlands plants: I. Duckweed. J. Environ. Qual. 1998, 27, 715-721. [CrossRef]

14. Huang, C.; Renew, J.; Sivieby, K. Assessment of potential antibiotic contaminants in water and preliminary occurrence analysis. Water Res. 2001, 120, 30-40.

15. Boonsaner, M.; Hawker, D.W. Accumulation of oxytetracycline and norfloxacin from saline soil by soybeans. Sci. Total Environ. 2010, 408, 1731-1737. [CrossRef] [PubMed]

16. Michelini, L.; Meggio, F.; La Rocca, N.; Ferro, S.; Ghisi, R. Accumulation and effects of sulfadimethoxine in Salix fragilis L. plants: A preliminary study to phytoremediation purposes. Int. J. Phytoremediation 2012, 14, 388-402. [CrossRef] 
17. Herklotz, P.A.; Gurung, P.; Heuvel, B.V.; Kinney, C.A. Uptake of human pharmaceuticals by plants grown under hydroponic conditions. Chemosphere 2010, 78, 1416-1421. [CrossRef]

18. Dettenmaier, E.M.; Doucette, W.J.; Bugbee, B. Chemical hydrophobicity and uptake by plant roots. Environ. Sci. Technol. 2009, 43, 324-329. [CrossRef] [PubMed]

19. Ashfaq, N.; Riffat, N.M.; Muhamamd, A.; Nasrullah, K.; Muhammad, F.S. Hyperaccumulators of heavy metals of industrial areas of Islamabad and Rawalpindi. Pak. J. Bot. 2011, 43, 1925-1933.

20. Ramesh, P.P.; Chu, L.L.; Kim, T.S.; Sohng, J.K. Bioconversion of tetracycline antibiotics to novel glucoside derivatives by single-vessel multienzymatic glycosylation. J. Microbiol. Biotechnol. 2018, 28, 298-304.

21. Kim, D.W.; Thomas, M.H.; Kim, B.S.; Laura, K.S.; Kellie, A.W.; John, B.S. Modification of norfloxacin by a Microbacterium sp. strain isolated from a wastewater treatment plant. Appl. Environ. Microbiol. 2011, 77, 6100-6108. [CrossRef]

22. Tzeng, T.W.; Liu, Y.T.; Deng, Y.; Hsieh, Y.C.; Tan, C.C.; Wang, S.L.; Huang, S.T.; Tzou, Y.M. Removal of sulfamethazine antibiotics using cow manure-based carbon adsorbents. Int. J. Environ. Sci. Technol. 2016, 13, 973-984. [CrossRef] 